\title{
Correction of First Web Space Deficiency in Congenital Deformities of the Hand with the Pseudokite Flap
}

\author{
Guy Foucher, M.D., José Medina, Ricardo Navarro, and Roger K. Khouri, M.D. \\ Strasbourg, France, Gran Canaria, Spain, and Miami, Fla.
}

\begin{abstract}
The authors describe a new flap to enlarge or create a first web in patients with congenital deficiencies of the hand. This lozenge-shaped flap is harvested from the dorsoradial aspect of the index finger based on a narrow proximal skin bridge protecting its axial vascularization. A dorsal skin graft of the donor site is avoided by closure using a rhomboid flap. Procedures in 16 patients were performed and reviewed; the only complication was insertion of a small split-thickness graft in five patients to avoid tension at the metacarpophalangeal joint level. The flap lengthened the web fold an average of $3.2 \mathrm{~cm}$ without "pseudolengthening" the thumb. (Plast. Reconstr. Surg. 107: 1458, 2001.)
\end{abstract}

The first web space is often contracted and deficient in congenital malformations of the hand. Of the many flaps described to release the contracted first web space, ${ }^{1-9}$ few are devoted to the specific problem of the congenital hand. ${ }^{10-14}$ Most of the described flaps require skin grafting of the donor site, leaving a conspicuous scar on the dorsum of the hand. We described the "pseudokite" in $1988^{15}$ to specifically address the congenital first web space deficiency and to avoid skin grafting of the flap donor site. This report is a review of our 14 years of experience with the pseudokite flap in 16 congenital hands, as we refined our technique and the indications for surgery.

\section{FLAP DESIGN}

The pseudokite flap is a lozenge-shaped flap harvested from the dorsoradial aspect of the index finger. It is an axial-pattern flap perfused by the first dorsal interosseous artery that courses along the radial aspect of the second metacarpal shaft. This is the constant nutrient artery of the "kite" island flap that was described by our group in 1979. ${ }^{16}$ The pseudokite is not a true island flap because it maintains a skin bridge a few millimeters wide at the base to protect the axial vessels.

The first incision starts proximally from point $\mathrm{A}$ at $1 \mathrm{~cm}$ radial to the midshaft of the second metacarpal to join point $\mathrm{B}$ at the middle of the web (Fig. 1, left). This $A B$ cut is extended on the volar aspect of the first web to point $\mathrm{A}^{\prime}$. Through this incision, the first web space is released, cutting any abnormal fibrous band $^{17}$ or muscle (lumbricalis pollicis ${ }^{18}$ ). The aponeurosis of the adductor muscle and the first interosseous muscle is also incised, with care taken to preserve the first dorsal interosseous vessels. The radial insertions of the first web muscles could be transferred proximally at this stage. The BC side of the lozenge is incised, along the midlateral radial line of the index finger $(\mathrm{BC}=\mathrm{BA})$. The two other sides of the lozenge are then incised, $\mathrm{CD}$ on the dorsolateral aspect of the index finger and DE on the dorsum of the hand. Point $\mathrm{E}$ is situated on the second metacarpal bone shaft, a few millimeters radial to point $\mathrm{A}$ to preserve the axial vascularization. The LLL plasty according to Dufourmentel ${ }^{19,20}$ is then drawn for future closing of the donor area, which is slightly different from the classic rhomboid design (Fig. 2). The BD and the ED lines are extended ulnarly, and the bisecting line is marked DF (DF being equal to all other sides of the lozenge). Finally, a perpendicular $\mathrm{FG}$ to the prolonged $\mathrm{AD}$ line $(\mathrm{FG}=\mathrm{DF})$ completes the surgical incisions. 

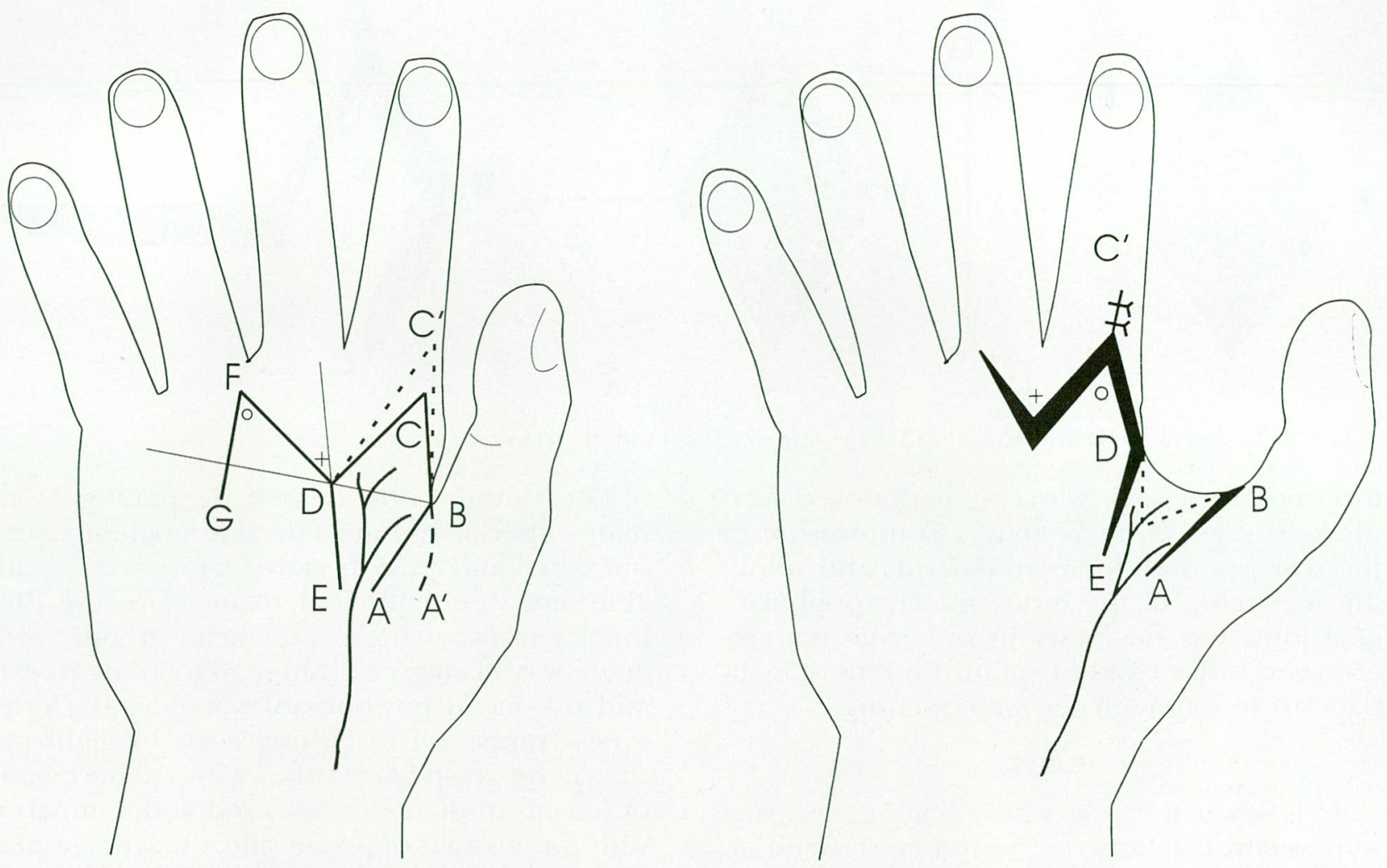

Fig. 1. Illustration of the pseudokite flap. (Left) Drawing of the flap on the laterodorsal aspect of the index finger with its arterial axis. (Right) Shifting of the flap in the first web, with donor-site closure by the Dufourmentel flap.

The lozenge flap is then elevated, and the dissection plane is kept deep to the aponeurosis of the first interosseous muscle to include the arterial branches of the first dorsal interosseous artery (Fig. 1). As in harvesting the kite flap, a major pitfall to be avoided is at the radial side of the metacarpal neck where the flap pedicle communicates by an anastomotic branch with the deep vessels. ${ }^{16}$ At this level, dissection must go deep inside the muscle to dissect and divide the anastomotic branch and to avoid cutting the nutrient artery. Although it is usually visible, it is not necessary to see the artery and it is dangerous to dissect it. When the skin lozenge remains attached only on its small AE skin bridge, the DFG flap is elevated, including only the skin. The lozenge flap is then transferred into the first web, point C coming in $\mathrm{A}^{\prime}$ position (Fig. 1, right). The LLL plasty ${ }^{19,20}$ consists of transposing the tip F in the C position, and the skin is entirely sutured. In fact, the donor area can be closed without tension only when the index metacarpophalangeal joint is maintained in extension. If this joint needs to stay flexed because of additional surgery, a small splitthickness skin graft is mandatory to avoid tension. This graft will retract with time, decreasing the size of the scar.

When a long palmar $\left(\mathrm{BA}^{\prime}\right)$ incision is necessary, $\mathrm{BC}^{\prime}$ and $\mathrm{DC}^{\prime}$ could be longer than $\mathrm{AB}$, $\mathrm{ED}, \mathrm{DF}$, and $\mathrm{FG}$. At this time, the $\mathrm{BC}^{\prime} \mathrm{D}$ angle is partially closed in a V-Y manner, until equalization of all sides of the lozenge is re-established (the vertical part of the $\mathrm{Y}$ is represented by the distance $\mathrm{CC}^{\prime}$ ).

\section{Patients}

Sixteen flap procedures were performed for congenital first web correction (Fig. 3). The mean age of the patients at the time of the surgical procedure was 10 months (range, 6 months to 6 years). The different indications according to the types of malformations are displayed in Table I (using the classification system of the International Federation of Societies for Surgery of the Hand).

In five patients, a split skin graft was required to avoid tension. A Kirschner wire was used in 10 patients to maintain the first web opening. The first dressing change was performed according to associated procedures, but never earlier than the second postoperative week, because resorbable sutures were used. When 

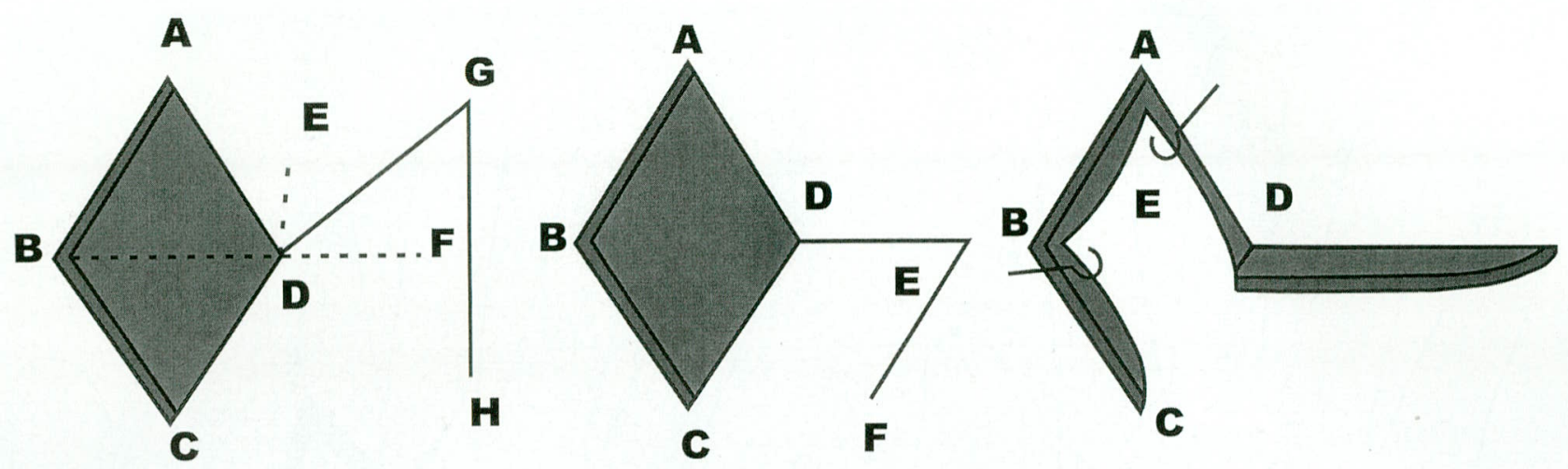

FIG. 2. Design of the Dufourmentel LLL flap (left) compared with the classic rhomboid (right).

inserted, Kirschner wires were removed at 3 weeks (range, 20 to 27 days). Compression of the scar was used in seven patients and splinting in flexion of the index metacarpophalangeal joint was necessary in only one patient; however, other types of splints were used in 11 patients to maintain the web opening.

\section{RESULTS}

As is often the case when dealing with first web reconstruction, we found it difficult to quantitatively assess the final result. In traumatic patients, many procedures have been proposed including measuring the radiological angle between first and second metacarpal, ${ }^{14}$ the distance between the pulp of the index finger and thumb, and the grasp of cylinders of increased diameter. None of these could be easily applied in patients with congenital hand malformation, and Friedman and Wood, ${ }^{14}$ in their article, dealt mainly with complications. Preoperatively and postoperatively, we measured the length of the thumb and the length of the first web (except in four patients with syndactyly) with a ruler to calculate the "apparent" lengthening of the thumb and the lengthening of the first web fold. This was done in the operating room before and immediately after the release to avoid any magnification caused by growth.

In our small series, there were instances of skin necrosis, wound dehiscence, skin graft slough, and index metacarpophalangeal joint residual stiffness. In two patients, healing overlying the metacarpophalangeal joint was slow (in one patient this was due to pressure of the splint).

The mean lengthening of the web fold was an average of $3.2 \mathrm{~cm}$ (a 205 percent increase) compared with preoperative measurement. There was no detectable "pseudolengthening" of the thumb (due to web deepening as in many other techniques). In seven patients, preoperative and postoperative x-rays were available and were sufficient to measure the first intermetacarpal angle. The mean preoperative angle was 11 degrees (range, 6 to 17 degrees), and the mean postoperative angle was 75 degrees (range, 54 to 89 degrees). In eight patients, the grasp of cylinders with an increment of $0.5 \mathrm{~cm}$ in diameter was used and compared with the normal opposite side, an average of 3 years after the operation (range, 7 months to 11 years). There was no discrepancy in five patients, a decrease of $1 \mathrm{~cm}$ in three patients, and a decrease of $2 \mathrm{~cm}$ in one patient. At the follow-up examination, all patients were satisfied and no reoperations were necessary.

\section{DISCUSSION}

Many techniques are available to treat a deficiency of the first web, but few articles deal specifically with congenital malformations. ${ }^{10-14}$ Besides tissue expansion, ${ }^{21}$ the described flaps could be local Z-plasties, simple or multiple flaps (four-flap, ${ }^{9}$ five-flap, ${ }^{2}$ butterfly flap, ${ }^{5}$ or Ostrowski's flap $^{3}$ ) (Fig. 4), or flaps taken from the dorsum of the thumb, ${ }^{4,7,10}$ the dorsum of the index finger, ${ }^{1,14}$ the lateral aspect of the index finger, ${ }^{22}$ or the dorsum of the hand. ${ }^{8,11,13}$ Caroli uses a dorsal and palmar flap, ${ }^{5}$ and distant donor sites could be selected either from the forearm (as a retrograde island flap) or from remote areas (pedicled or free). ${ }^{22}$

We found it difficult to have a "favorite" technique, and the pseudokite flap was used in 16 cases out of a series of 99 congenital hands treated for a deficiency of the first web space. In fact, all of the techniques are useful and the choice of the best one is dependent on many factors, namely, the patient's age at correction and the type of malformation. In some malfor- 

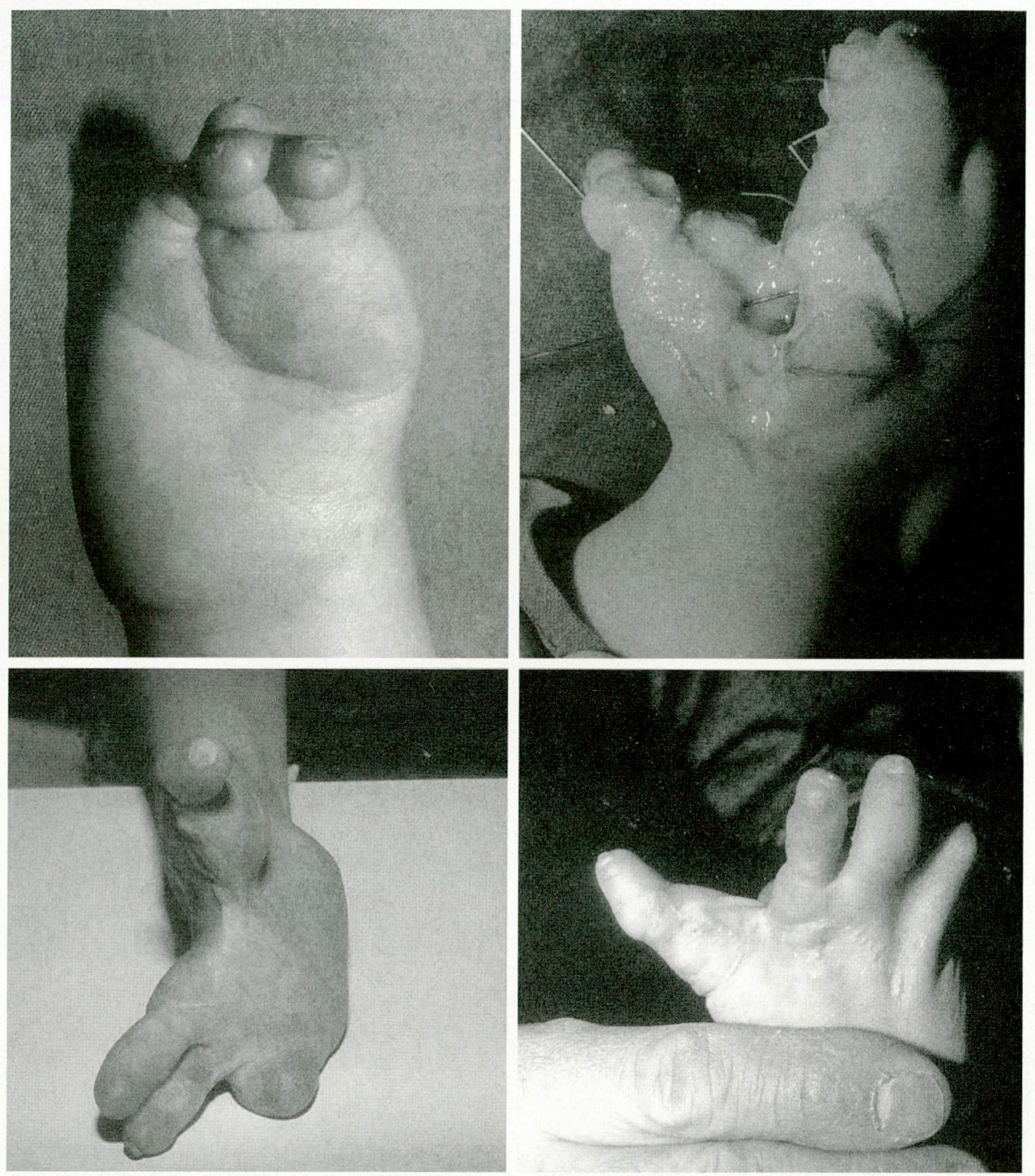

FIG. 3. Illustration of a patient with a congenital band syndrome treated with a pseudokite flap. (Above, left) A complete thumb-index finger syndactyly. (Above, right) Perioperative view with web opening and flap designing. (Below) Final results demonstrating the reconstructed first web and the dorsal scar.

mations the web exists and in others it is absent; in some patients, the hand is narrow, the thumb is hypoplastic, and the index finger may be absent.

One aspect that has been overlooked in the literature is the "relative" thumb (and index finger) lengthening in many of the first web plasties. The deepening effect of the plasty could be an advantage when the thumb and/or index finger are short, but it is a major cosmetic drawback when their length is normal. This is seen with Ostrowski et al., ${ }^{3}$ Tajima, ${ }^{1}$ or Buck-Gramcko ${ }^{8}$ flaps, for example. On the other hand, the Woolf and Broadbent ${ }^{9}$ fourflap Z-plasty gives moderate deepening with major lengthening but could only improve an existing web. To "create" a completely deficient web, apart from distant flaps, only flaps from the dorsum of the thumb, index finger, or hand can be used. Many of these are combined with skin grafting and leave a conspicuous scar. ${ }^{1,4,6-8,10,12,14}$

The advantages of the "pseudokite flap" are (1) ample web fold lengthening, without "relative" thumb lengthening; (2) wide exposure of the restraining element of the web (e.g., the muscles, aponeurosis, and fibrous bands) along with access to the extensor indicis proprius muscle when necessary (thumb hypoplasia type III ${ }^{23,24}$ ); (3) good distal contour of the 
TABLE I

Types of Congenital Malformations Undergoing Surgery*

\begin{tabular}{ll}
\hline & $n$ \\
\hline Thumb-index syndactyly & \\
Isolated complete/incomplete & \\
Part of a syndrome & 2 \\
Apert syndrome (spoon type) & 1 \\
Symbrachydactyly (spoon type) & 1 \\
Amniotic band syndrome & \\
Insufficient first web & 5 \\
Thumb hypoplasia & 5 \\
Type II & 1 \\
Type IIIA and B & 1 \\
Thumb in palm & 1 \\
Freeman-Sheldon syndrome & \\
Recurrence after previous correction & \\
$\quad$ (thumb-index syndactyly in a & \\
central deficiency)
\end{tabular}

* Using the classification system of the International Federation of Societies for Surgery of the Hand.

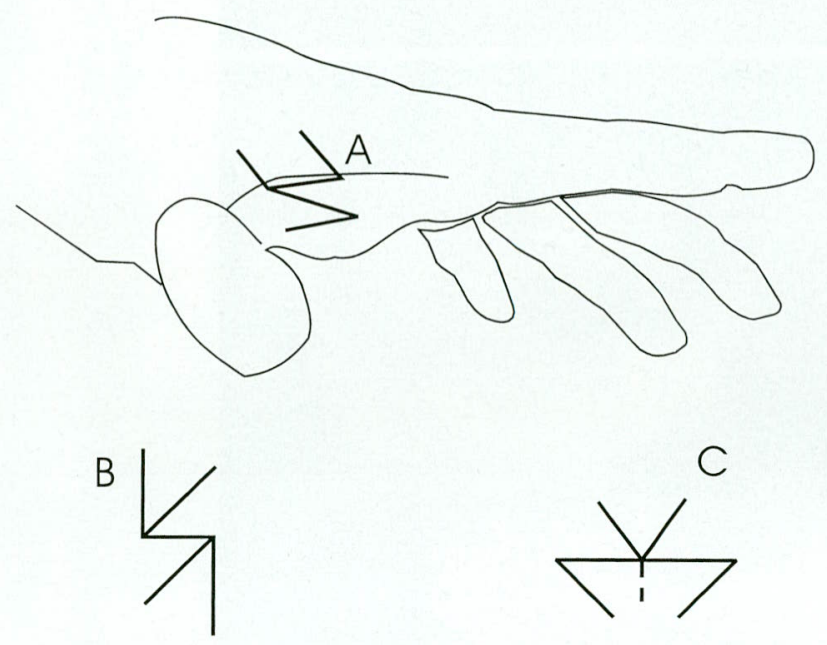

FIG. 4. Illustrations of the Z-plasties. (A) Ostrowski's flap. (B) Four-flap plasty. (C) Butterfly plasty.

web space (no angle as in some Z-plasties) the tetrahedral flap is what is needed when the web space is opened ${ }^{25}$; (4) the procedure is easy to perform and is reliable due to its axial vascularization ${ }^{16}$; (5) there is good flap mobility, because the flap is nearly an island; and (6) the donor site on the lateral aspect of the index finger is closed entirely by a local flap, ${ }^{19,20}$ avoiding conspicuous skin grafting.

This procedure is, however, contraindicated when there is already a scar on the dorsal aspect of the hand, and we have not used it when the index finger is absent (despite the fact that a dorsal metacarpal artery is available in each space). Because it does not deepen the web, it does not provide the pseudolengthening effect that may be desirable when the thumb is short.
In conclusion, our experience with the pseudokite flap confirms its usefulness for creating or improving a deficient first web in selected cases of congenital malformations of the hand. Guy Foucher, M.D. 4 Boulevard du président Edwards Strasbourg 67000, France ifssh@aol.com

\section{REFERENCES}

1. Brand, P. Hand reconstruction in leprosy. In British Surgical Practice: Surgical Progress. London: Butterworth, 1954. Pp. 117-130.

2. Hirshowitz, B., Karev, A., and Rousso, M. Combined double Z-plasty and V-Y advancement for thumb web contracture. Hand 7: 291, 1975.

3. Ostrowski, D. M., Feagin, C. A., and Gould, J. S. A three flap web plasty for release of short congenital syndactyly and dorsal adduction contracture. J. Hand Surg. (Am.) 16: 634, 1991.

4. Sandzen, S. C., Jr. Dorsal pedicle flap for resurfacing a moderate thumb-index web contracture release. J. Hand Surg. (Am.) 7: 21, 1982.

5. Shaw, D. T., Li, C. S., Richey, D. G., and Nahigian, S. H. Interdigital butterfly flap in the hand (the double-opposing Z-plasty). J. Bone Joint Surg. (Am.) 55: $1677,1973$.

6. Spinner, M. Fashioned transpositional flap for soft tissue adduction contracture of the thumb. Plast. Reconstr. Surg. 44: 345, 1969.

7. Strauch, B. Dorsal thumb flap for release of adduction contracture of the first web space. Bull. Hosp. Joint Dis. 36: 34, 1975.

8. Tajima, T. Classification of thumb hypoplasia. Hand Clin. 1: 577, 1985.

9. Woolf, R. M., and Broadbent, T. R. The four-flap Zplasty. Plast. Reconstr. Surg. 49: 48, 1972.

10. Blauth, W. Zur Behandlung der verengten Daumen Kommissur mit der "erweiterten Schwenllappenplastik." Handchirurgie 8: 71, 1976.

11. Buck Gramko, D. Syndactyly between the thumb and index finger. In D. Buck Gramko (Ed.), Congenital Malformations of the Hand and Forearm. London: Churchill Livingstone, 1998. Pp. 141-147.

12. Caroli, A., and Zanasi, S. First web-space reconstruction by Caroli's technique in congenital hand deformities with severe thumb ray adduction. Br. J. Plast. Surg. 42: $653,1989$.

13. Flatt, A. E., and Wood, V. E. Multiple dorsal rotation flap from the hand for thumb web contractures. Plast. Reconstr. Surg. 45: 258, 1970.

14. Friedman, R., and Wood, V. E. The dorsal transposition flap for congenital contracture of the first web space: A 20-year experience. J. Hand Surg. (Am.) 22: 664, 1997.

15. Foucher, G., Cornil, C., and Braga Da Silva, J. Le lambeau "pseudo-cerf-volant" de l'index avec plastie LLL dans la reconstruction de la première commissure. Ann. Chir. Plast. Esthet. 37: 207, 1992.

16. Foucher, G., and Braun, J. B. A new island flap transfer from the dorsum of the index to the thumb. Plast. Reconstr. Surg. 63: 344, 1979.

17. Lösch, G. M., and Schrader, M. Connective tissue structures in the first intermetacarpal space in case of mal- 
formations of the hand with and without syndactyly. Chir. Plast. (Berl.) 4: 145, 1978.

18. Lister, G. Musculus lumbricalis pollicis. J. Hand Surg. (Am.) 16: 622, 1991.

19. Dufourmentel, C. La fermeture des pertes de substance cutanée limitées "Le Lambeau de rotation en L pour Losange.” Ann. Chir. Plast. 7: 61, 1962.

20. Lister, G. D., and Gibson, T. Closure of rhomboid skin defects: The flaps of Limberg and Dufourmentel. Br.J. Plast. Surg. 25: 300, 1972.

21. Coombs, C. J., and Mutimer, K. L. Tissue expansion for the treatment of complete syndactyly of the first web. J. Hand Surg. (Am.) 19: 968, 1994.
22. Upton, J., Havlik, R. J., and Coombs, C. J. Use of forearm flaps for the severely contracted first space in children with congenital malformations. J. Hand Surg. (Am.) 21: 470, 1996.

23. Foucher, G., Gazarian, A., and Pajardi, G. La chirurgie reconstructive dans les hypoplasies type III de Blauth. Chir. Main 18: 191, 1999.

24. Manske, P. R., McCaroll, H. R., Jr., and James, M. Type III-A hypoplastic thumb. J. Hand Surg. (Am.) 20: 246, 1995

25. Littler, J. W. Principles of reconstructive surgery of the hand. In J. J. Converse (Ed.), Reconstructive Plastic Surgery. Philadelphia: Saunders, 1964. Pp. 1620-1624. 